\title{
BIOFOULING E BIODETERIORAÇÃO QUÍMICA DE ARGAMASSA DE CIMENTO PORTLAND EM RESERVATÓRIO DE USINA HIDROELÉTRICA
}

\author{
Kleber Franke Portella* e Alex Joukoski \\ Departamento de Tecnologia em Materiais, Instituto de Tecnologia para o Desenvolvimento, CP 19067, 81531-980 \\ Curitiba - PR, Brasil \\ Ariel Scheffer da Silva, Nicole Machuca Brassac e Carlos Eduardo Belz \\ Departamento de Recursos Ambientais, Instituto de Tecnologia para o Desenvolvimento, CP 19067, 81531-980 \\ Curitiba - PR, Brasil
}

Recebido em 6/5/08; aceito em 16/10/08; publicado na web em 12/2/09

\begin{abstract}
BIOFOULING AND CHEMICAL BIODETERIORATION IN HYDROELETRIC POWER PLANT PORTLAND CEMENT MORTAR. Last decade Brazilian rivers experimented progressive biofouling of Limnoperna fortunei communities and Cordylophora caspia hydroids. The microhabitat is so favorable that in around 1.5 years L. fortunei increased from 0.39 to nearby 149,000 units/ $\mathrm{m}^{2}$. Ten Portland cement mortar samples were produced with 1: 3.5: 0.4 dosages and installed for 1 year at Salto Caxias Brazilian Power Plant reservoir in $0.5 \mathrm{~m}$ and $1.0 \mathrm{~m}$ deep to investigate the biofouling influence on hydraulic civil structures. SEM, EDS, visual investigation and XRF results indicate none direct chemical interrelationships between $L$. fortunei and the mortar samples. However C. caspia diminished the mortar surface resistance and caused cement paste leaching.
\end{abstract}

Keywords: Portland cement mortar; biofouling; Limnoperna fortunei.

\section{INTRODUÇÃO}

As estruturas de concreto das áreas de geração hidroelétrica necessitam ter resistência mecânica suficiente para suportar o próprio peso e, principalmente, as cargas ocasionadas pela retenção e canalização das águas para movimentação das máquinas hidráulicas. Com este objetivo, grandes reservatórios são produzidos, constituindo meios ideais para a proliferação de micro e macroorganismos, tais como as espécies exóticas do hidrozoário Cordylophora caspia e do molusco Limnoperna fortunei, conhecido como mexilhão dourado, atualmente disseminadas pelos rios e reservatórios brasileiros. Estes organismos encontram-se presentes no reservatório da Usina Hidroelétrica Governador José Richa (UHE GJR) ou UHE Salto Caxias, a cerca de $600 \mathrm{~km}$ de Curitiba. A região vem sendo tão propícia à sua fixação e evolução que, em menos de um ano e meio, a densidade populacional dos mexilhões dourados cresceu de 0,37 para cerca de 149.000 indivíduos $/ \mathrm{m}^{2}$, com diâmetro médio de suas conchas em torno de 36 mm. ${ }^{1,2}$ Pode-se, desta forma, inferir sobre a seriedade do problema gerado a estes empreendimentos.

A bioacumulação ou biofouling, termo que se refere à formação de depósitos biológicos sobre a superfície de equipamentos ou instalações industriais e, neste caso, de superfícies hidráulicas, pode trazer como consequiência efeitos deletérios adversos. Destacam-se os processos corrosivos ou bioeletroquímicos e a diminuição da vazão ou entupimento de adutoras e dutos, principalmente se estes são responsáveis pela refrigeração hidráulica de máquinas rotativas que operam sob baixas temperaturas, como as turbinas para a geração de energia elétrica. Além disto, tem-se a possibilidade de que a fixação destes organismos cause alterações químicas superficiais ou biodeterioração, em virtude de seus processos metabólicos com geração de substâncias poliméricas extracelulares e secundárias, tais como os ácidos orgânicos. ${ }^{3}$

*e-mail: portella@lactec.org.br
No reservatório da UHE GJR, o biofouling vem ocorrendo, principalmente, sobre a grade da tomada de água e nas paredes de concreto das câmaras das comportas de descarregamento do reservatório. ${ }^{1} \mathrm{O}$ objetivo deste estudo foi verificar se esta fixação ocasiona a deterioração química das estruturas de concreto e argamassas locais.

\section{PARTE EXPERIMENTAL}

\section{Composição química dos insumos, dosagem de argamassa e confecção das placas}

A composição físico-química do cimento Portland modificado com pozolana, tipo CPII-Z, classe 32, foi investigada conforme recomendações de normas técnicas brasileiras. ${ }^{4}$ Parte da composição química foi determinada por fluorescência de raios X, em equipamento Philips, modelo PW 2400.

A areia natural lavada para a confecção das argamassas ou corpos-de-prova foi analisada por métodos petrográficos e físicos, ${ }^{4}$ principalmente, para verificação de sua distribuição granulométrica, taxa de absorção de água e índice de porosidade.

$\mathrm{O}$ traço de argamassa das placas de amostragem foi trabalhado com cimento pozolânico, classe 32, tipo CPII-Z 32 e areia natural lavada, com diâmetro médio do agregado miúdo menor que $4,8 \mathrm{~mm}$. A melhor relação de traço, obtida a partir dos insumos cimento, areia e água, foi de 1:3,5:0,4. Foram elaboradas 10 placas similares.

\section{Instalação das placas na UHE GJR}

A instalação das placas ou corpos-de-prova (CPs) foi feita na estrutura flutuante (log-boom), situada no reservatório a montante da tomada d'água da barragem, nas profundidades de 0,5 e $1 \mathrm{~m}$, sendo 5 CPs em cada uma delas. As fotos do local e dos CPs encontram-se mostradas na Figura 1. 


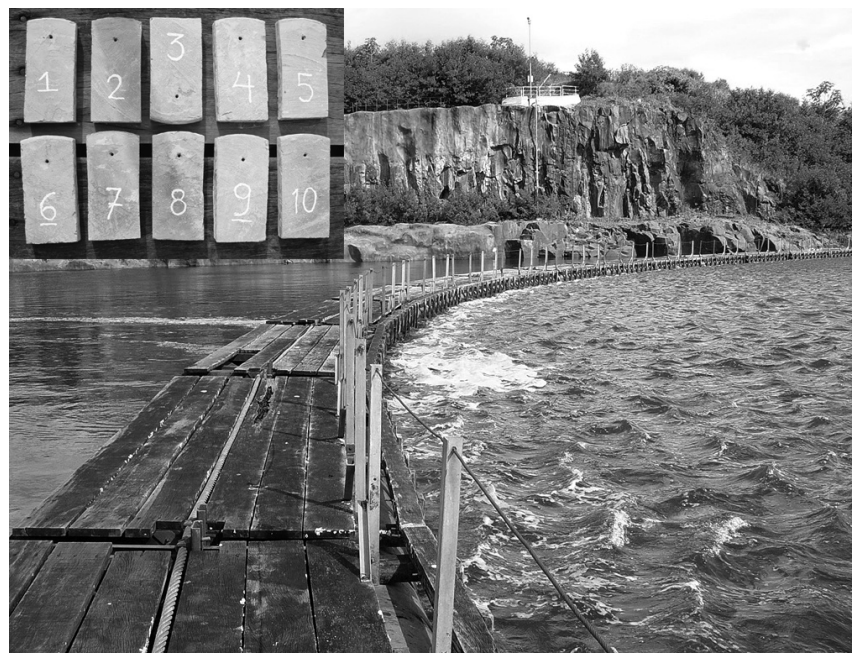

Figura 1. Vista geral do log-boom da UHE GJR. No detalhe, os CPs instalados

\section{Investigação e registro fotográfico}

Os CPs foram investigados por inspeção visual ao longo do tempo. Em todas as ocasiões foram feitos registros fotográficos das comunidades aderidas.

\section{Caracterização físico-química dos CPs}

Após 1 ano de imersão, os CPs foram superficialmente limpos por extração e lavagem mecânicas do material aderido em sua superfície, sendo medida a massa resultante após secagem em estufa a $110{ }^{\circ} \mathrm{C} / 12 \mathrm{~h}$.

\section{Perda ao fogo}

Todo o material seco foi pesado em balança digital e sua massa comparada com a resultante da sua queima a $1000{ }^{\circ} \mathrm{C}$. A diferença foi calculada em termos percentuais.

\section{Análise química do material aderido}

O material resultante da perda ao fogo foi analisado em termos de sua composição química elementar em espectrômetro de fluorescência de raios X (FRX), marca Philips, modelo PW 2400. O material foi previamente moído e prensado em pastilhas de bórax.

\section{Inspeção visual}

Durante a retirada dos hidrozoários e mexilhões aderidos, foram realizadas investigações e registros fotográficos da textura das superfícies dos CPs e dos comprometimentos locais ocasionados pela extração ou retirada dos mesmos. Todos os CPs foram submetidos aos mesmos procedimentos, com posterior lavagem manual com escova.

\section{Microscopia eletrônica de varredura (MEV) e análise elementar por microssonda analítica de raios $\mathrm{X}$, EDS}

Micrografias com diferentes ampliações foram obtidas a partir da metalização, via pulverização catódica com ouro, da superfície de análise de cada CP. A composição química qualitativa elementar foi analisada nos próprios locais investigados. Foi utilizado um microscópio eletrônico de varredura Philips, modelo XL 30, com microssonda analítica, marca EDAX.

\section{RESULTADOS E DISCUSSÃO}

\section{Investigação química dos insumos trabalhados}

Todos os parâmetros físico-químicos analisados no cimento resultaram dentro do especificado pelo fabricante e em norma, com exceção para o $\mathrm{Na}_{2} \mathrm{O}$ equivalente, cujo valor foi superior e pode induzir a uma reatividade potencial com agregados reativos. ${ }^{3,4} \mathrm{~A}$ sua composição química está apresentada na Tabela 1.

Tabela 1. Resultados das análises físico-químicas do cimento CPIIZ 32

\begin{tabular}{lcc}
\hline Análises & Resultados $(\%)$ & $\begin{array}{c}\text { Limites } \\
\text { normalizados }(\%)^{4}\end{array}$ \\
\hline Óxido de alumínio $\left(\mathrm{Al}_{2} \mathrm{O}_{3}\right)$ & 6,59 & - \\
Dióxido de silício $\left(\mathrm{SiO}_{2}\right)$ & 21,93 & - \\
Óxido férrico $\left(\mathrm{Fe}_{2} \mathrm{O}_{3}\right)$ & 3,29 & - \\
Óxido de cálcio $(\mathrm{CaO})$ & 54,26 & - \\
Óxido de magnésio $(\mathrm{MgO})$ & 4,02 & Máximo: 6,50 \\
Anidrido sulfúrico $\left(\mathrm{SO}_{3}\right)$ & 3,00 & Máximo: 4,00 \\
Perda ao fogo & 5,13 & Máximo: 6,50 \\
Resíduo insolúvel & 13,44 & Máximo: 16,00 \\
Óxido de cálcio livre & 1,59 & 1,00 a 2,00 \\
Equivalente alcalino & 0,85 & Máximo: 0,60 \\
$\left(\mathrm{Na}{ }_{2} \mathrm{O}+0,658 \mathrm{~K}_{2} \mathrm{O}\right)$ & & \\
\hline
\end{tabular}

A caracterização física dos agregados miúdos apresentou resultados dentro do especificado. ${ }^{4} \mathrm{~A}$ sua análise petrográfica resultou ser composta de quartzo e não reativa a álcalis.

$\mathrm{O}$ valor médio da resistência mecânica à compressão axial do cimento, aos 28 dias, foi de $40 \pm 2,1 \mathrm{MPa}$.

\section{Inspeção das placas de concreto}

A primeira inspeção nos CPs foi realizada depois de 3 meses de imersão. Os registros fotográficos foram efetuados depois de avaliados quanto à presença do hidrozoário C. caspia e do "bivalve" L. fortunei. Até os 8 primeiros meses de imersão, foram apenas observadas colônias do hidrozoário sobre a superfície do substrato, conforme mostrado na Figura 2. Entre 8 e 12 meses, houve a fixação do $L$. fortunei sobre toda a área exposta do $\mathrm{CP}$ e sobre o próprio $C$. caspia, já aderido, conforme pode ser visualizado na Figura 3. A maior concentração de ambos foi observada nas placas submersas a $1 \mathrm{~m}$ de profundidade.

\section{Análise dos CPs após extração dos organismos aderidos}

Os mexilhões dourados, apesar da grande quantidade na superfície, não aderiram firmemente ao substrato. As suas estruturas de fixação, denominadas bissos, na forma de fios de escleroproteínas, foram facilmente arrancadas manualmente com pinça.

As colônias do hidrozoário C. caspia e a microbiota associada, ao contrário, demonstraram possuir um sistema de fixação bastante aderente, causando, inclusive com seu arrancamento, o desplacamento superficial da pasta de cimento, conforme pode ser observado na foto mostrada na Figura 4. Este comportamento já havia sido observado nas superfícies hidráulicas de concreto da própria barragem. 


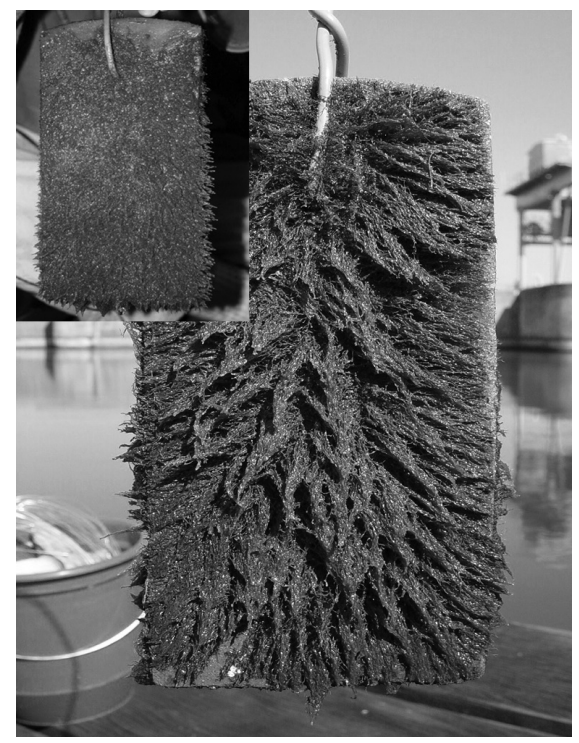

Figura 2. Biofouling de hidrozoário C. caspia sobre um dos CPs imersos no reservatório da UHE GJR por 8 meses. Na imagem menor, o mesmo CP após 3 meses de imersão

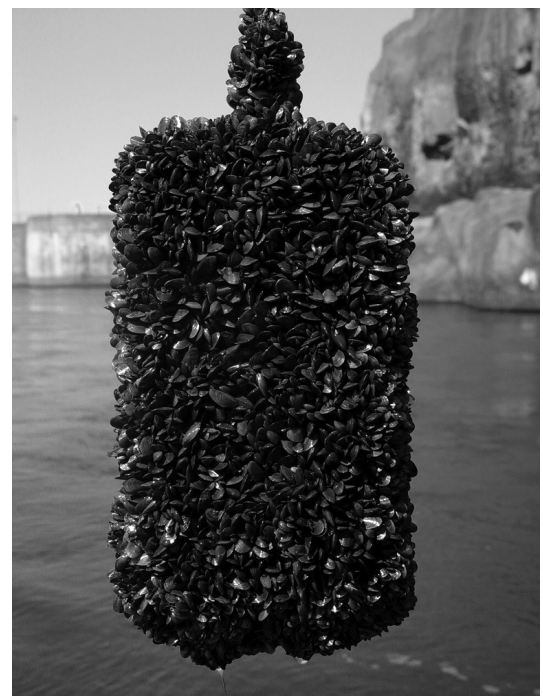

Figura 3. Biofouling de L. fortunei (mexilhão dourado) na superfície de um dos CPs, após 12 meses de imersão no reservatório da UHE GJR

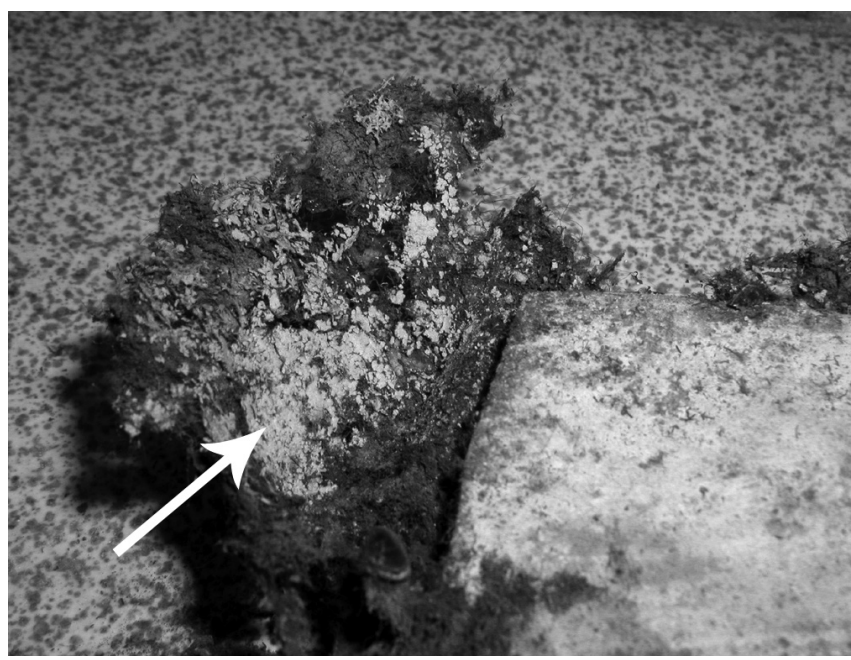

Figura 4. Foto da superfície do CP após extração do C. caspia. A seta indica parte da argamassa desplacada com o hidrozoário arrancado

\section{MEV e análise química elementar semiquantitativa com EDS}

Na micrografia apresentada na Figura 5 está mostrada a forma de fixação do hidrozoário $C$. caspia na superfície do $\mathrm{CP}$ de argamassa, entre os agregados (setas indicativas). Observa-se, neste caso, que sua aderência resistiu aos trabalhos de pré-tratamento da estrutura, constituídos de lavagem, raspagem e vácuo para a análise por MEV.

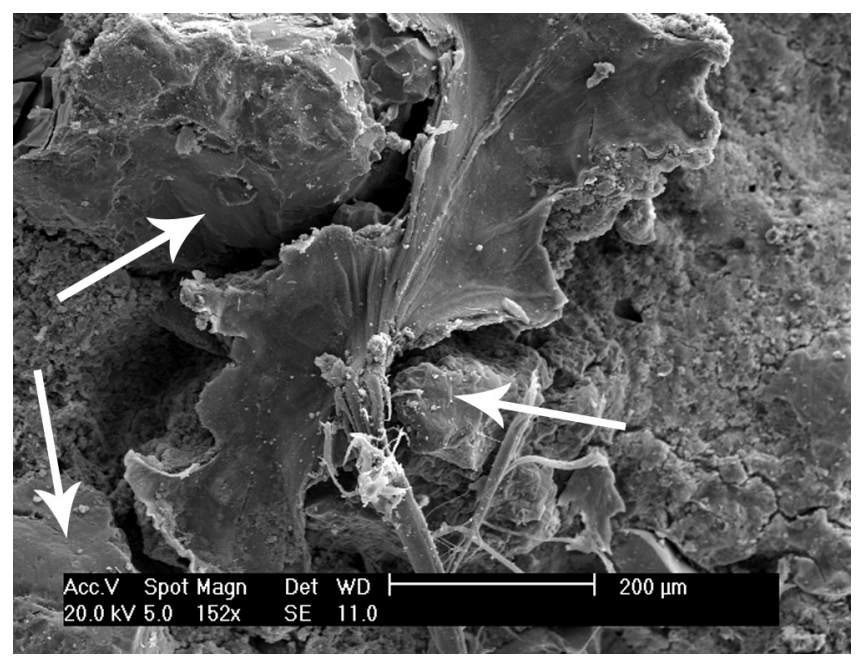

Figura 5. Foto ilustrativa da forma de fixação dos hidrozoários aderidos. As setas indicam os agregados

Observou-se pelas micrografias por MEV que as colônias destes hidrozoários formaram uma malha de filamentos horizontais aderidos ao substrato. Desses, saíram filamentos verticais modulares ramificados, com estruturas reprodutivas e de alimentação. A sustentação das colônias deste tipo de hidróide é dada pelo perisarco, ou seja, por uma cobertura quitinosa, geralmente envolta por uma delgada camada de muco. Esta rede de filamentos forma um "micro-habitat" específico, permitindo o desenvolvimento de uma comunidade biológica associada, composta por bactérias, microalgas diatomáceas e por diversos microinvertebrados aquáticos.

Na Figura 6, podem ser observadas várias frústulas de algas diatomáceas, principalmente as espécies do gênero Gomphonema.

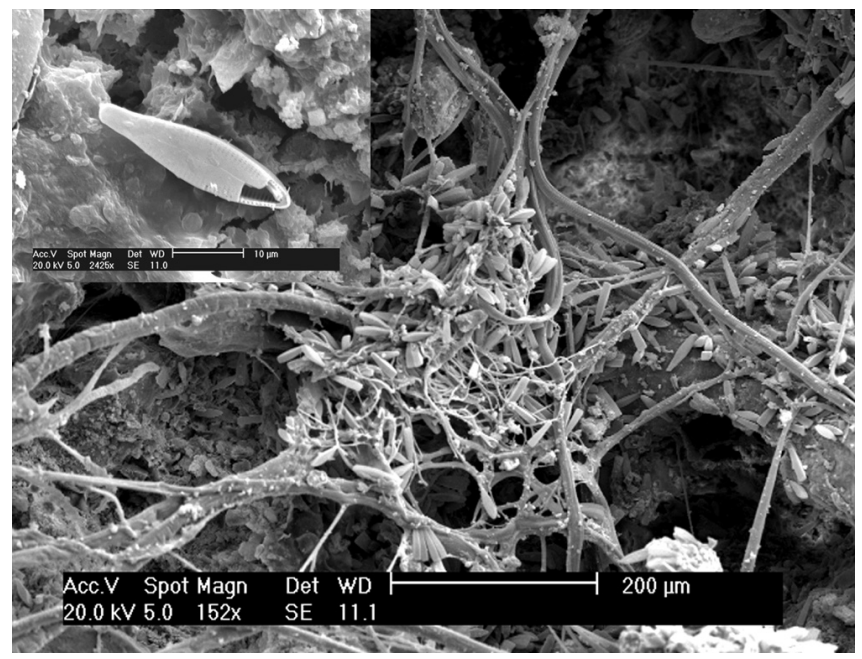

Figura 6. Micrografia do CP com os filamentos do hidrozoário e de várias frústulas de diatomáceas, principalmente do gênero Gomphonema. Em detalhe, uma frústula de G. cf. brasiliense, parcialmente fragmentada 
Nos detalhes, vê-se a $G$. cf. brasiliense sobre uma rede de filamentos orgânicos e uma frústula desta espécie, parcialmente fragmentada pelos procedimentos adotados no pré-tratamento do $\mathrm{CP}$ correspondente. Seu mesoesqueleto foi determinado quimicamente por EDS, sendo composto de sílica. Este material, denominado comercialmente como terra de diatomácea, vem sendo utilizado em diversos ramos da indústria. ${ }^{5}$

As micrografias dos CPs, por MEV, mostradas na Figura 7, composta pela argamassa-referência, e, no detalhe, depois de extraídos os organismos, apresentam características de lixiviação da pasta de cimento. Este processo pode ser conseqüente, também, da extração de elementos químicos, tais como cálcio e sílica ou silicatos, necessários aos metabolismos dos microorganismos presentes, seguidos pela erosão superficial com susceptibilidade de ataque ambiental. ${ }^{3}$

A dissolução, seguida da lixiviação de componentes da pasta de cimento, está fundamentada no processo de geração de substâncias poliméricas extracelulares, com produção de metabólitos secundários e de substâncias, como ácidos carbônico e ascórbico, pelos organismos incrustantes. ${ }^{6-8}$

O aproveitamento de substâncias do substrato por hidróides pode acontecer pelos processos de seqüestro de carbonato de cálcio por células gastrodérmicas, via metabolismo citoquímico, tanto em larvas quanto em organismos adultos. ${ }^{9}$

A composição química e mineralógica do substrato influencia no processo de incrustação e de sucessão ecológica da biota aquática, existindo preferências de certos organismos por substratos ricos em carbonatos, como os próprios hidrozoários estudados. Há outros microorganismos, como as esponjas, que preferem superfícies ricas em quartzo, sendo estas preferências associadas ao metabolismo de crescimento e à formação de estruturas de sustentação. O exoesqueleto dos hidrozoários é formado por compostos químicos como quitina e proteínas ricas em ligações por dissulfetos. ${ }^{7,10}$

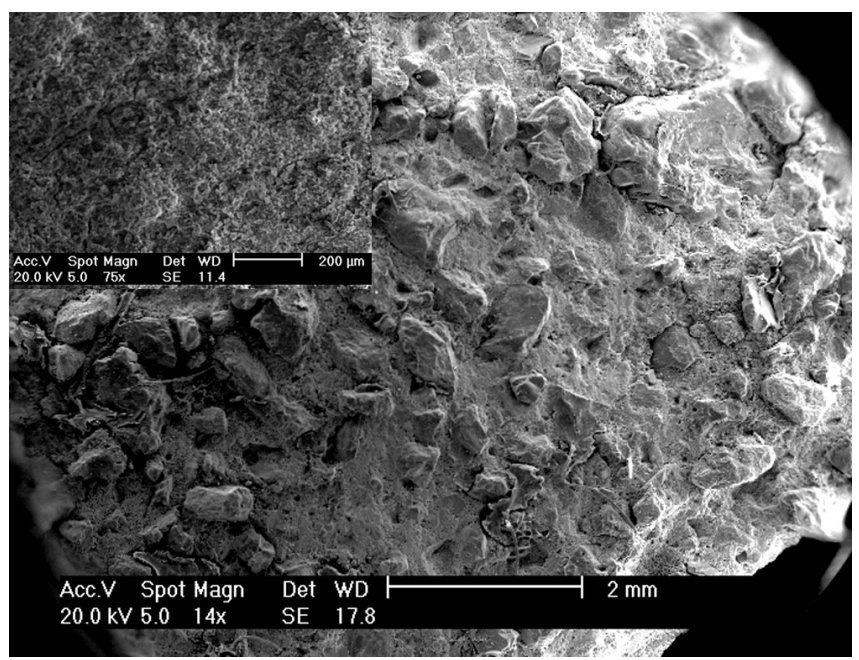

Figura 7. Micrografia ampliada da superfície de um CP de argamassareferência. No detalhe, superfície de outro $C P$ similar após extração dos hidrozoários

Independente do processo químico resultante certificou-se a perda de resistência mecânica superficial dos CPs, cuja camada foi arrancada com a extração conjunta dos hidrozoários aderidos. Normalmente, tal perda é conseqüência da dissolução da pasta de cimento que se inicia pela extração dos sais dissolvidos nos poros e, posteriormente, do cálcio presente na pasta de cimento. ${ }^{11}$ Também pode ser conseqüente de mecanismos biogeoquímicos que, a partir da produção biogênica de ácidos orgânicos e inorgânicos, acaba induzindo ao processo de lixiviação ácida dos minerais. ${ }^{3}$
Os resultados das análises químicas realizadas por FRX, tanto do mexilhão dourado quanto do hidrozoário, após o teste da perda ao fogo, encontram-se apresentados na Tabela 2. Destaca-se a presença de $\mathrm{SiO}_{2}, \mathrm{Al}_{2} \mathrm{O}_{3}, \mathrm{SO}_{3}, \mathrm{Fe}_{2} \mathrm{O}_{3}, \mathrm{~K}_{2} \mathrm{O}$ e $\mathrm{MgO}$ em maior percentual no hidrozoário. Apesar da sua estrutura conter fases químicas semelhantes às do cimento, embora com teores distintos e, também, de haver indicativos na literatura ${ }^{3,9}$ de seqüestro de minerais por microorganismos similares, não se pode inferir que esta seja resultante, exclusivamente, dos materiais presentes na superfície dos CPs. Há casos em que os seus metabolismos encontram-se associados aos seus meios de imersão. ${ }^{3}$

O composto de cálcio, determinado no L. fortunei é relativo à sua estrutura de concha ou "bivalve". Segundo Bessler e Rodrigues, ${ }^{12}$ os exoesqueletos de corais e moluscos consistem preferencialmente da fase aragonita $\left(\mathrm{CaCO}_{3}\right)$.

\section{Perda ao fogo}

A perda ao fogo média dos organismos fixados nas superfícies dos CPs foi de 52,03 $\pm 0,10 \%$, sendo atribuída, principalmente, à perda de umidade, à matéria orgânica e à descarbonatação das conchas do L. fortunei.

Tabela 2. Composição química dos resíduos dos microorganismos $L$. fortunei e C. caspia retirados da superfície das placas de argamassa, após perda ao fogo

\begin{tabular}{lccccccccc}
\hline $\begin{array}{l}\text { Microorga- } \\
\text { nismo }\end{array}$ & $\begin{array}{c}\mathrm{CaO} \\
(\%)\end{array}$ & $\begin{array}{c}\mathrm{SiO}_{2} \\
(\%)\end{array}$ & $\begin{array}{c}\mathrm{Fe}_{2} \mathrm{O}_{3} \\
(\%)\end{array}$ & $\begin{array}{c}\mathrm{Al}_{2} \mathrm{O}_{3} \\
(\%)\end{array}$ & $\begin{array}{c}\mathrm{SO}_{3} \\
(\%)\end{array}$ & $\begin{array}{c}\mathrm{Na}_{2} \mathrm{O} \\
(\%)\end{array}$ & $\begin{array}{c}\mathrm{MgO} \\
(\%)\end{array}$ & $\begin{array}{c}\mathrm{K}_{2} \mathrm{O} \\
(\%)\end{array}$ \\
\hline L. fortunei & 81,4 & 0,4 & 0,2 & 0,1 & 0,5 & 0,3 & 0,2 & $<0,1$ \\
C. caspia & 12,7 & 41,8 & 12,3 & 16,7 & 2,8 & 0,3 & 1,3 & 0,6 \\
\hline
\end{tabular}

\section{CONCLUSÃO}

O estudo de fixação do L. fortunei e do hidrozoário C. caspia sobre as estruturas de argamassa de cimento Portland, conformadas em placas finas imersas a $1 \mathrm{~m}$ de profundidade no reservatório da UHE GJR, permitiu inferir que os mexilhões dourados não possuem mecanismos de aderência prejudiciais à estrutura, podendo ser facilmente removidos por tratamento mecânico de limpeza e lavagem superficial. Entretanto, pela quantidade aderida, este poderá causar diminuição dos volumes úteis e entupimento de dutos de refrigeração e grelhas de escoamento de usinas hidroelétricas.

Os hidrozoários, por sua vez, aderem firmemente ao substrato, formando uma rede de filamentos distribuída por toda a superfície do $\mathrm{CP}$, permitindo, inclusive, a ancoragem de algas diatomáceas, como as pertencentes ao gênero Gomphonema, encontradas na amostra. Os terminais destes filamentos estavam fixados, normalmente, na pasta de cimento, entre os agregados.

O arrancamento dos hidrozoários por processo mecânico manual aconteceu com parte da pasta de cimento, indicando ter havido perda da resistência mecânica desta última. Em função das micrografias obtidas pode-se supor que seja conseqüente ou de um processo metabólico, pela ação de ácidos orgânicos, ou da extração de componentes químicos elementares do cimento, como cálcio e silício. Tais compostos são vitais para sua permanência e proliferação.

\section{AGRADECIMENTOS}

À COPEL, ao LACTEC e à ANEEL, pelo suporte financeiro e infra-estrutura para a execução do projeto de pesquisa. 


\section{REFERÊNCIAS}

1. Belz, C. E.; Tese de Doutorado, Universidade Federal do Paraná, Brasil, 2006.

2. Darrigran, G.; Aliens 1997, 5, 3.

3. Videla, H. A.; Biocorrosão, biofouling e biodeterioração de materiais, $1^{\mathrm{a}}$ ed., Edgard Blücher: São Paulo, 2003; Taylor, H. F. W.; Cement Chemistry, Academic Press: London, 1990.

4. Associação Brasileira de Normas Técnicas, NBR 5743, ABNT, Rio de Janeiro, 1989; NBR 5744, ABNT, Rio de Janeiro, 1989; NBR 5745, ABNT, Rio de Janeiro, 1989; NBR 5747, ABNT, Rio de Janeiro, 1989; NBR 7227, ABNT; Rio de Janeiro, 1989; NBR 9203, ABNT, Rio de Janeiro, 1985; NBR 8347, ABNT, Rio de Janeiro, 1986; NBR 11579, ABNT, Rio de Janeiro, 1991; NBR 11581, ABNT, Rio de Janeiro, 1986; NBR 11582, ABNT, Rio de Janeiro, 1986; NBR NM 23, ABNT, Rio de Janeiro, 2001; NBR NM 76, ABNT, Rio de Janeiro, 1998; NBR NM 248, ABNT, Rio de Janeiro, 2003; NBR 7211, ABNT, Rio de Janeiro, 2005; NBR 7218, ABNT, Rio de Janeiro, 1974; NBR 7219, ABNT, Rio de Janeiro, 1987; NBR 7220, ABNT, Rio de Janeiro, 1976; NBR 9776, ABNT, Rio de Janeiro, 1977; NBR NM 30, ABNT, Rio de Janeiro, 2001.

5. Vidotti, E. C.; Rollemberg, M. da C. E; Quim. Nova 2004, 27, 139.

6. Cady, S. L.; Farmer, J. D.; Proceedings of Evolution of Hydrothermal Ecosystems on Earth (and Mars?), Chichester, UK, 1996.

7. Di Camillo, C.; Puce, S.; Romagnoli, T.; Tazioli, S.; Totti, C.; Bavestre1lo, G.; J. Mar. Biol. Assoc. 2006, 86, 1285.

8. Bavestrello, G.; Bianchi, C. N.; Calcinai, B.; Cattaneo-Vietti, R.; Cerrano, C.; Morri, C.; Puse, S.; Sara, M.; Mar. Ecol. Prog. Ser. 2000, 193, 241.

9. Pomponi, S. A.; J. Mar. Biol. Assoc. 1979, 59, 777.

10. Dandar-Roh, A. M.; Rogers-Lowery, C. L.; Zellman, E.; Thomas, M. B.; J. Morphology 2004, 260/2, 255; Chapman, G.; Growth 1937, 1, 299; Bouillon, J.; Levi, C.; Z. Zellforsch. 1971, 121, 218.

11. Biczok, I.; Corrosión y protección del hormigón, Urmo: Bilbao, 1981.

12. Bessler, K. E.; Rodrigues, L. C.; Quim. Nova 2008, 31, 178. 